\title{
Stage IV Vaginal Cancer AJCC v6 and v7
}

National Cancer Institute

\section{Source}

National Cancer Institute. Stage IV Vaginal Cancer A/CC v6 and v7. NCI Thesaurus. Code C7597.

Stage IV includes: IVA: (T4, Any N, M0) and IVB: (Any T, Any N, M1). T4: T umor invades mucosa of the bladder or rectum and/or extends beyond the true pelvis (bullous edema is not sufficient evidence to classify tumor as T4). M0: No distant metastasis. M1:

Distant metastasis. (AJCC 6th and 7th eds.) 